\section{Perceptions of active zumba members regarding the concept of "zumba": A metaphor analysis study ${ }^{1}$}

\section{Aktif zumbaya katılan üyelerin "zumba" kavramına ilişkin algıları: Bir metafor analizi çalışması}

\author{
Gizem Ceylan ${ }^{2}$ \\ Melek Kozak ${ }^{3}$
}

\begin{abstract}
The purpose of this research is to determine the perceptions of the members participating in active zumba about the concept of "Zumba" with the help of metaphor. The research group consisted of 94 volunteers living in Ankara (age $=32.57 \pm 9.91$ years) and doing active zumba in various gyms. In the research, as a data collection tool, a "metaphor form" was prepared to determine the participants' perceptions about the concept of zumba. The research data were collected with the metaphor form sentence is written "Zumba is like ...; because...." As the metaphors obtained in the research are used as a descriptive tool, one of the qualitative research approaches; content analysis was used.For the reliability of the analysis of the research data, the reliability coefficient between the participants was calculated and this value was found to be $97 \%$. When the data were evaluated, it was determined that active zumba participant members produced a total of 35 metaphors. These metaphors were collected in 5
\end{abstract}

\section{Özet}

$\mathrm{Bu}$ araştırmanın amacı, aktif zumbaya katılan üyelerin 'Zumba' kavramına ilişkin sahip oldukları alg1ları metafor yardımıyla belirlenmesidir. Araştırma grubunu Ankara'da yaşayan (yaş $=32,57 \pm 9,91$ yll) çeşitli spor salonlarinda aktif zumba yapan 94 gönüllü oluşturmuş̧tur. Araştırma da veri toplama aracı olarak katılımcılara zumba kavramına ilişkin sahip oldukları algılarını belirlemek için "metafor formu" hazırlanmıştır. Araştırma verileri "Zumba...gibidir, Çünkü..."cümlesinin yazılı olduğu metafor formuyla toplanmıştır. Araştırmada elde edilen metaforlar bir betimleme arac1 olarak kullanıldığından nitel araştırma yaklaşımlarından içerik analizi kullanılmıştır. Araştırma verilerinin analizinin güvenirliği için katılımcılar aras1 güvenirlik kat sayısı hesaplanmış ve bu değer \%97 olarak bulunmuştur. Veriler değerlendirildiğinde, aktif zumba katılımcisı üyelerinin toplam 35 metafor ürettiği görülmüştür. Üretilen bu metaforlar 5 kategoride toplanmıştır. Katılımcıların zumba

${ }^{1}$ Bu çalışmanın bir kısmı 2-5 Mayıs 2019 tarihleri arasında Muş’ta düzenlenen 2. Uluslararası Avrasya Kongresi'nde sözel bildiri olarak sunulmuştur.

2Arş. Gör., Muş Alparslan Üniversitesi, Spor Bilimleri Fakültesi; gizemcyln.87@gmail.com

(iD) Orcid ID: 0000-0003-4456-7589

${ }^{3}$ Arş. Gör., Karamanoğlu Mehmet Bey Üniversitesi, Spor Bilimleri Fakültesi, melek.kozak@gmail.com (iD) Orcid ID: 0000-0002-5279-2703 
Ceylan, G., \& Kozak, M. (2021). Aktif zumbaya katılan üyelerin “zumba” kavramına ilişkin algıları: Bir metafor analizi çalışması. Journal of Human Sciences, 18(2), 233-242. doi:10.14687/jhs.v18i2.6149

categories. While it was determined that the participants mostly developed metaphors related to the concept of zumba in the categories of "pleasure" and "feeling of happiness", these categories were followed by "health", "psychological benefit" and "socialization". The metaphors most produced by the participants are listed as entertainment, dance, chocolate, sports, lifestyle and life energy. As a result; in research for the concept of "zumba" of the participants; it has been determined that they use living, inanimate, abstract and concrete metaphors.

Keywords: Zumba, Sport, Metaphor, Qualitative Research Method.

(Extended English summary is at the end of this document) kavramına ilişkin en çok "haz" ve "mutluluk hissi" kategorisinde metaforlar geliştirdikleri belirlenirken, bu kategorileri "sağllk", "psikolojik fayda" ve "sosyalleşme" kategorileri izlemiştir. Katılımcıların en fazla ürettiği metaforlar eğlence, dans, çikolata, spor, yaşam biçimi ve hayat enerjisi şeklinde sıralanmıştır. Sonuç olarak; araştırmada katılımcıların "zumba" kavramı için; canlı, cansiz, soyut ve somut metaforlar kullandikları belirlenmiştir.

Anahtar Kelimeler: Zumba, Spor, Metafor, Nitel Araştırma Yöntemi.

\section{Giriş}

Dans, temel bedensel hareketler ve müzik eğitimi ile birlikte ritim yeteneğinin gelişmesini sağlayan (Altay ve Bulca, 2006), kişinin öğrenme ve performans unsurlarını kapsayan ve aynı zamanda akademik açıdan da spor ve egzersiz bilimleri çatısı altında bulunan bir yapıya sahiptir. Dolayısıyla dans, sporla iç içe bir kavram olarak birçok alanla özellikle egzersiz ile ilişkilendirilmektedir (Gök ve ark., 2019).

Aerobik danslar, step aerobik ve kültürel danslar gibi alışılmıșın dışında ki fiziksel aktivite biçimleri, özellikle kadınlar için eğlenceli, heyecan verici ve psikolojik olarak olumlu duygular hissettirdiğinden dolayı tercih edilmektedir. Bedensel ve ruhsal olarak sağlıklı olmanın dışında, fitness eğitim alanında ortaya çıkan faaliyetlerden birisi de zumbadır (Cugusi ve ark., 2019).

Zumba; soca, samba, salsa, merengue ve mambo gibi latin ritimlerini, farklı hareketler, eğlence ve zindelikle birleştiren müzik ve dans hareketlerini içeren bir fitness rutinidir (Schneekloth ve Brown, 2018). Bir yaşam tarzı egzersizi olan zumba, 1990'ların ortalarında ünlü fitness eğitmeni Alberto "Beto" Perez tarafindan Columbia'da geliştirilen latin esintili bir dans egzersizidir. Zumba, Beto'nun geleneksel aerobik müziğini sınıfa getirmeyi unuttuğunda "tesadüfen" geliştirilmiştir. Beto, birkaç latin müzik kaseti ile, sınıfta bir klüpteymiş gibi müziğin kendisini motive etmesine izin vererek, salsa, rumba ve merengue ile dans etmeye başlamıştır. Zumba'nın bu kadar yaygınlaşmasının nedenlerinden biri, Beto'nun "bunu yapmanın doğru veya yanlış bir yolu olmadığını" iddia etmesidir. Zumba, daha çok bir dans partisidir ve katılımcılar müziğin ritmine uymaya teşvik edilerek, koreografiler diğer grup egzersiz sınıflarından daha samimidir. Zumba'nın popüler sloganı ise: "Antrenmanı boşver: partiye katıl!" olarak öne çıkmaktadır (Luettgen ve ark., 2012).

Metafor temel olarak bir nesne veya olayın belli özelliklerini açıklamaya yönelik bir araçtır. Metaforlar bulguları iletmenin güçlü ve zeki yollarından biridir. Güçlü bir metafor tek bir ibare ile çok fazla anlam ifade edebilir (Patton, 2014). Metaforlar, yeterince benzer fakat farklı bir şekilde düşünceler ifade edilebilir. Metaforlar uyum sağlamaya yardımcı olur ve psikolojik iç görüleri kolayca anlaşlan mesajlara dönüştürebilir (Spandler ve ark., 2013). 
Ceylan, G., \& Kozak, M. (2021). Aktif zumbaya katılan üyelerin "zumba” kavramına ilișkin algıları: Bir metafor analizi çalışması. Journal of Human Sciences, 18(2), 233-242. doi:10.14687/jhs.v18i2.6149

Günümüzde yaygın bir şekilde kadınların ilgisini çeken zumba dans, birçok birey tarafindan kolayca öğrenilebilinecek bir aktivitedir. Aktif zumbaya katılan üyelerin zumbayı nasıl gördükleri, ne düşündükleri, neye veya nelere benzettikleri ve nelerle ilişkilendirdiklerini metaforlar yöntemi ile belirlemek araştırmanın amacını oluşturmaktadır.

Literatür incelendiğinde spor bilimleri alanında metafor ile ilgili yapılan çalışmalara rastlamak mümkündür (Spandler ve ark., 2013; Kurtipek ve ark., 2017; ; Kurtipek ve Güngör, 2018; Kurtipek ve Sönmezoglu, 2018; Dursun ve ark., 2019; Kurtipek, 2019; Kurtipek ve Güngör, 2019a; Kurtipek ve Güngör, 2019b; Adaş ve ark., 2020; Kozak ve ark., 2020; Bayköse ve ark., 2021) fakat bu çalışmalar incelendiğinde daha çok spora ve farklı spor branşlarına ait olduğu gözlemlenmiştir. Dolayısıyla bu çalışma aktif zumba yapan bireylerin zumba kavramına yönelik algılarını açıklamaya çalışmaları ve alanda yapılacak araştırmalara farklı bir bakış sunması açısından önem arz etmektedir.

\section{Araştırma Deseni}

\section{YÖNTEM}

Nitel araştırma modeline göre hazırlanan bu çalışmada olgu-bilim(fenomoloji) deseni kullanılmıştır. Olgu-bilim deseni, farkında olduğumuz ancak derinlemesine ve ayrıntılı bir anlayışa sahip olmadığımız olgulara odaklanmaktadır (Creswell, 2013; Yıldırım ve Şimşek, 2014).

\section{Araştırma Grubu}

Fenomolojik (olgubilim) desenli bir araştırmada örneklem seçim stratejisi oldukça dar bir aralıkta olup araştırmaya katılacak bireylerin çalışılan fenome yönelik deneyimlerinin olması şartına uygun olarak amaçlı örnekleme yöntemi kullanılmıştır (Creswell, 2020). Çalışma grubu oluşturulurken amaçlı örneklem yöntemlerinden ölçüt örnekleme kullanılmıştır. (Büyüköztürk ve ark., 2009).Ölçüt örnekleme, önceden belirlenmiş bir dizi ölçütü karşılayan durumların çalışılmasıdır. Ölçüt ya da ölçütler araştırmacı tarafından oluşturulabilir (Yıldırım ve Şımşek, 2014).

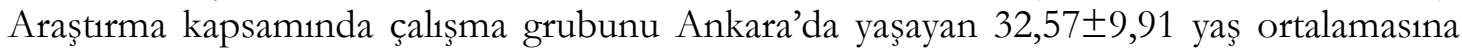
sahip çeşitli spor salonlarında aktif olarak zumba yapan 93 kadın oluşturmuştur. Katılımcıların çalışmaya gönüllü katılmak istemesi gibi kriterler dikkate alınarak veri toplama işlemi gerçekleşmiştir.

\section{Veri Toplama Arac1}

Araştırmada veri toplamak amacıyla katılımcıların zumba kavramına ilişkin sahip oldukları algılarını belirlemek için "metafor formu" hazırlanmıştır. Formda yer alan sorular "Google Form" aracılığıly hazırlanarak, anketin katılımcılara daha kolay ulaşması amaçlanmıştır. Katıllımcılara eposta adresleri ve sosyal medya uygulamaları üzerinden anketin tanıtım metni ve online form linki gönderilmiştir. Anket, 15 gün boyunca erişime açık kalmış, veri girişinin sonlanmasıyla anket durdurularak, veri seti analiz için hazır hale getirilmiştir. Katılımcılardan zumba kavramına ilişkin bir metafor yazmaları ve bu metaforu neden yazdıklarını, zumba kavramının kendilerine neden bu çağrışımı yaptığını bir cümle ile açıklamaları istenmiştir. Formda katılımcıların zumba algılarına ilişkin olarak; "Zumba ...gibidir, Çünkü...” cümlesini doldurmaları istenmiştir.

\section{Verilerin Analizi}

Araştırmada elde edilen metaforlar bir betimleme aracı olarak kullanıldığından verilerin analizinde nitel araştırma yaklaşımlarından içerik analizi kullanılmıştır. İçerik analizi, verilerin tanımlanması, kodlanması ve kategorileştirilmesi sürecidir (Patton, 2014). Verilerin analizine başlamak için öncelikle katılımcıların formları K1'den K93'e kadar numaralandırılmıştır. Araştırmada katılımcıların belirttikleri metaforların içerik analiziyle değerlendirilmesi ve yorumlanması; eleme, derleme, geçerlilik ve güvenirliliğin sağlanması, metaforların frekanslarının hesaplanması ve kategorilendirilmesi şeklinde yapılmıştır. Araştırmanın güvenirliğini sağlamak için ise, veri analizi sonucunda ulaşılan kavramsal kategorilerin elde edilen temaları temsil edip etmediğini belirlemek amacıyla 3 alan uzmanı tarafından veriler analiz edilmiş; elde edilen kodlar ve kodların temsil ettiği kategoriler karşılaştırılmıştır. Araştırma verileri 3 araştırmacı tarafından ayrı ayrı kodlandıktan sonra ortaya çıkan kod ve kategori listesine son şekli verilmiştir. Bu şekilde yapılan veri analizinin güvenirliği; [Görüş birliği / (Görüş birliği + Görüş ayr1lığı) x 100] formülü 
Ceylan, G., \& Kozak, M. (2021). Aktif zumbaya katılan üyelerin “zumba” kavramına ilişkin algıları: Bir metafor analizi çalışması. Journal of Human Sciences, 18(2), 233-242. doi:10.14687/jhs.v18i2.6149

kullanılarak hesaplanmıştır (Miles ve Huberman, 1994). Araştırmada toplam 35 metafor üretilmiş olup, 94 görüş içerisinden görüss ayrılığı olan 1 metafor(su)belirlenmiştir. Kodlayıcılar arasındaki ortalama güvenirlik \%97 olarak bulunmuştur [34 / (34+ 1) x 100=\%97]. Bu sonuç, araştırmada istenilen güvenirlik düzeyine ulaşıldığını göstermektedir.

\section{BULGULAR}

Çalışmamızda öncelikle aktif zumba katılımcısı bireylerin zumba kavramına yönelik sahip oldukları metaforlar kodlanmıs, kategorilere ayrılmış ve bu kategorilerin temaları oluşturulurken zumba ile ilişkilendirilebilecek temalar oluşturulmuştur. Yapılan analizler sonucunda veriler beş kategori altında toplanmış ve ortaya çıkan bulgular bu kısımda okuyucuya sunulmuştur.

\section{Tablo 1. Aktif Zumbaya Katılan Üyelerin 'Zumba' Kavramına İlişkin Geliştirdikleri}

\section{Metaforlar}

\begin{tabular}{|c|c|c|c|c|c|}
\hline $\begin{array}{c}\text { Metafor } \\
\text { Sirasi }\end{array}$ & $\begin{array}{c}\text { Metafor } \\
\text { Adı }\end{array}$ & $\mathbf{f}$ & $\begin{array}{c}\text { Metafor } \\
\text { Sirasi }\end{array}$ & $\begin{array}{c}\text { Metafor } \\
\text { Adı }\end{array}$ & $\mathbf{f}$ \\
\hline 1 & Eğlence & 18 & 19 & Çilek & 1 \\
\hline 2 & Dans & 12 & 20 & Kahve & 1 \\
\hline 3 & Çikolata & 4 & 21 & Arkadaş & 1 \\
\hline 4 & Spor & 4 & 22 & Tatli & 1 \\
\hline 5 & Yaşam biçimi & 4 & 23 & Doğum & 1 \\
\hline 6 & Hayat Enerji & 4 & 24 & Tutku & 1 \\
\hline 7 & Terapi & 4 & 25 & Antidepresan & 1 \\
\hline 8 & Hobi & 3 & 26 & Serotonin Hormonu & 1 \\
\hline 9 & Zayıflamak & 3 & 27 & Doping & 1 \\
\hline 10 & Canll11k & 3 & 28 & Temel ihtiyaç & 1 \\
\hline 11 & Mutluluk & 3 & 29 & Yaşam zevki & 1 \\
\hline 12 & Oyun & 3 & 30 & Kafa dağıtmak & 1 \\
\hline 13 & Motivasyon & 2 & 31 & Aradığımı bulmak & 1 \\
\hline 14 & Aktivite & 2 & 32 & Deşarj & 1 \\
\hline 15 & Özgürlük & 2 & 33 & Göklerde Uçmak & 1 \\
\hline 16 & $\mathrm{Su}$ & 2 & 34 & Sağlik & 1 \\
\hline 17 & Özgüven & 2 & 35 & Mutluluk Yağmuru & 1 \\
\hline 18 & Her Şey & 2 & & TOPLAM GÖRÜŞ & 94 \\
\hline
\end{tabular}

Tablo 1 incelendiğinde; aktif zumbaya katılan üyelerin 'zumba' kavramına yönelik toplam 35 çeşit metafor ürettikleri ve bunun için 94 görüş belirttikleri görülmektedir. En yüksek frekansa sahip metafor, eğlence (18) metaforu olmuştur. Bunun dişında dans (12) çikolata (4), spor (4), yaşam biçimi (4) ve hayat enerjisi(4) metaforlarının frekansları diğerlerinden daha yüksektir.

Metaforlara yönelik kategori belirleme işleminden sonra öğrencilerin belirttiği ifadelere göre kelime bulutu oluşturulmuştur (Şekil 1).

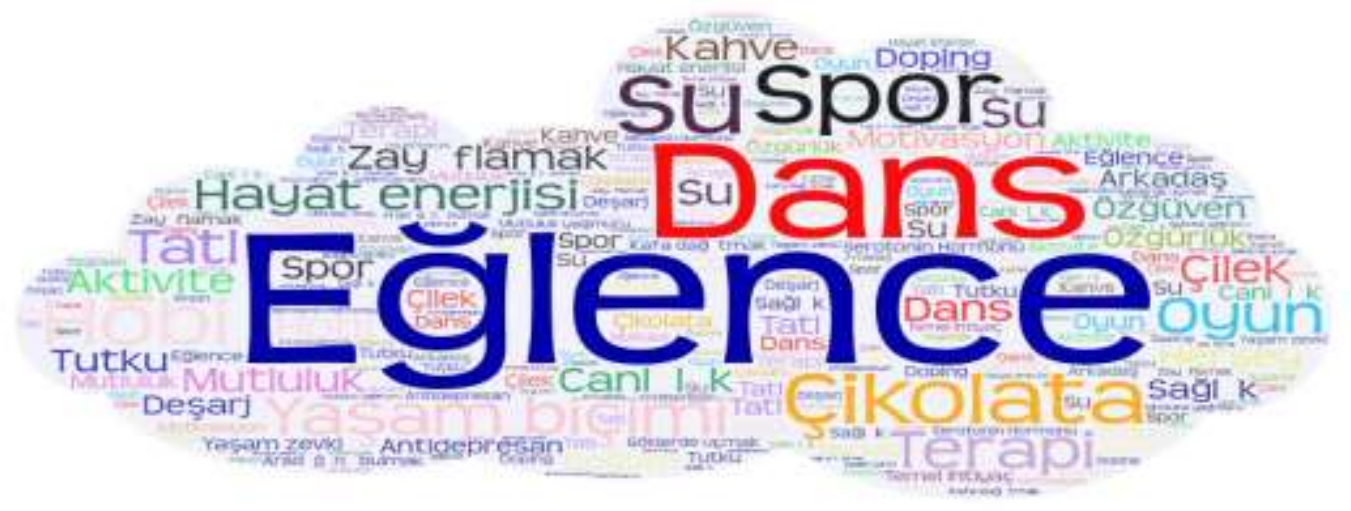

Şekil 1. Metafor ifadelerine yönelik kelime bulutu 
Ceylan, G., \& Kozak, M. (2021). Aktif zumbaya katılan üyelerin “zumba” kavramına ilişkin algıları: Bir metafor analizi çalışması. Journal of Human Sciences, 18(2), 233-242. doi:10.14687/jhs.v18i2.6149

Kelime bulutuna göre katılımcıların en çok 'eğlence', 'dans', 'çikolata', 'yaşam biçimi', 'hayat enerjisi', 'terapi' gibi ifadeleri dile getirdikleri belirlenmiştir. Yapılan kodlamalarsonucunda en yüksek oranda "Mutluluk Hissi" ve "Haz" kategorisinin vurgulandiğ1 düşünülürse kelime bulutunun da bu şekilde çıkması beklenen birdurum olarak görülmektedir.Aktif zumbaya katılan üyelerin 'zumba' kavramına yönelik görüşleri açıklamaları ile birlikte değerlendirildiğinde beş kategori olarak sınıflandırılması Tablo 2’de gösterilmiştir.

Tablo 2. Aktif Zumbaya Katılan Üyelerin 'Zumba' Kavramına Yönelik Belirttikleri Metaforların Kategorilere Göre Dağılımı

\begin{tabular}{lll}
\hline Kategoriler & Metafor say1si (f) & $\mathbf{\%}$ \\
\hline Psikolojik fayda & 8 & 22,85 \\
\hline Sağllk & 5 & 14,28 \\
\hline Mutluluk hissi & 13 & 37,14 \\
\hline Haz & 5 & 14,28 \\
\hline Sosyalleşme & 4 & 11,42 \\
\hline TOPLAM & $\mathbf{3 5}$ & $\mathbf{1 0 0 . 0}$ \\
\hline
\end{tabular}

Tablo 2'de katılımcıların belirttikleri metaforların kategorik analizi verilmiştir. Buna göre metaforlar "psikolojik fayda" ( $\mathrm{f}=8, \% 22,85)$, "sağlık" ( $\mathrm{f}=5 \%$ \%14,28), "mutluluk hissi" ( $\mathrm{f}=13$ \%37,14), "haz" (f=5 \%14,28) ve "sosyalleşme" (f=4, \%11,42) olarak toplam 5 kategori altında toplanmiştır.

Tablo 3. Kategorilere Göre Yer Alan Metaforlar ve Açıklama Örnekleri

\begin{tabular}{lll}
\hline Kategori & Metafor (f) & Zumba Üyelerinin açıklama örneklerinden alıntılar; \\
\hline & Özgüven (2) & \\
& Terapi(4) & Deşarj; zevkli ve fazla kalori yaktırdığından dolayı zumba \\
& Antidepresan(1) & benim deşarj demektir çünkü mutlu hissettirir. (K70) \\
Psikolojik & Deşarj(1) & Terapi; beni rahatllyor ve enerji doluyorum. (K40, K48) \\
Fayda & Kafa dağıttmak(1) & Doping; üzgün de olsanız sizi canlandır ve içinizdeki üstün \\
& Tutku(1) & enerjiyi ortaya çıkarır. (K13) \\
& Doping (1) & Özgüven; rahatça hareket edebildiğim bir alan. (K6) \\
& Yaşam zevki(1) & \\
\hline
\end{tabular}

Spor(4)

Sağlık Sağlık(1)

Temel ihtiyaç(1)

Seratonin hormonu(1)
Zayiflamak(3)

Spor; kalori yakıyorum. (K65)

Zayıflamak; kendim, sağlığım ve ruhum için zayıflamaya ihtiyacım var. (K60)

Temel İhtiyaç; kilo vermemi sağlayan, eğlendiren, en önemlisi sağlığıma katkısının bulunması.(K34)

Serotonin Hormonu; zumbaeğlenceli ve toplu yapılan bir fiziksel etkinlik bu sebeple insanları depresyondan uzaklaştırır. Beynimiz serotonin ve dopamin gibi mutluluk hormonları salgıladığı için Zumba=mutluluk (serotonin) ,Zumba=sağlık. (K84)

Çikolata (4)

Çilek(1)

Kahve (1)

Tatli(1)

Doğum (1)

Göklerde uçmak (1)

Motivasyon (2)

Canlilik (3)

Dans (12)

Aradığını bulmak(1)

Mutlu olmak (3)

Mutluluk yağmuru (1)

$\mathrm{Su}(2)$
Çikolata; ikisi de beni mutlu ediyor. (K3)

Doğum; başlangıç acılı ama sonu mutluluk veriyor. (K82)

Motivasyon; kendimi daha iyi hissettiriyor. (K67)

Mutluluk yağmuru; kendimi daha genç ve özel hissediyorum. (K86).

Tatlı; sen sevdiğim tatlıyı da keyif alarak yiyorum sonrasında da mutlu oluyorum(K80) 
Ceylan, G., \& Kozak, M. (2021). Aktif zumbaya katılan üyelerin "zumba” kavramına ilișkin algıları: Bir metafor analizi çalışması. Journal of Human Sciences, 18(2), 233-242. doi:10.14687/jhs.v18i2.6149

$\begin{array}{ll} & \text { Eğlence(18) } \\ & \text { Yaşam biçimi(4) } \\ \text { Haz } & \text { Hayat enerjisi(4) } \\ & \text { Her şey(2) } \\ & \text { Özgürlük(2) }\end{array}$

Hobi (3)

Oyun(3)

Arkadaş(1)

Aktivite(2)

$\begin{array}{ll}\text { Sosyalleşme } & \text { Oyun(3) } \\ & \text { Arkadaş(1) } \\ & \text { Aktivite(2) }\end{array}$

Ĕ̆lence; hem spor yapmış hem keyif almış oluyorum ve sonuç olarak eğleniyorum. (K23)

Yaşam biçimi; ruhuma iyi gelen bir yanı var iyi hissetmemi sağliyor. (K50)

Hayat Enerjisi; negatif duygularımdan arınıorum daha mutlu hissediyorum kendimi. (K54)

Her şey; hayat yaşam su yemek içmek gibi her şey ya kısaca. (K71).

Özgürlük; zumba yaparken uçuyor gibi hissediyorum sadece kanatlarım eksik. (K77)

Hobi; kendime vakit ayırdığım tek ortam kendimi evden çıarak bir gruba dahil etmemi sağlıyor. (K57)

Oyun; hem oyun oynuyorum hem bir grup arkadaş edinmiş oluyorum evden çıkıyorum daha nolsun. (K66)

Arkadaş; bana iyi gelen bir dost gibi. Sanki dostumla dertleşmiş gibi oluyorum sosyalleşiyorum (K58)

Tablo 3'te "Psikolojik fayda" kategorisinde belirtilen toplam 8 metafor ve aç1klama cümleleri incelendiğinde; zumba ile katılımcılar kendilerini enerji dolu hissettikleri ve özgüven sağladığına vurgu yapmaktadırlar. "Sağlık" kategorisinde belirtilen toplam 5 metafor ve açıklama cümleleri incelendiğinde; katılımcılar zumbanın hem fiziksel hem de ruhsal sağllğga olumlu etkilerinin olduğunu belirtmişlerdir." Mutluluk hissi" kategorisinde belirtilen toplam 13 metafor ve açıklama cümleleri incelendiğinde; katılımcılar kendilerini daha iyi, keyifli ve özel hissettiklerine vurgu yaptıkları anlaşılmaktadır. "Haz" kategorisinde toplam 5 metafor belirtilmiştir. Açıklama ifadelerinden de anlaşıldığı gibi katılımcıların, zumbayı ruhuna doyum sağlayan bir araç olarak gördükleri anlaşılmaktadır. "Sosyalleşme" kategorisinde ise 4 metafor belirtilmiştir. Açıklama ifadelerinden de anlaşıldığı üzere katılımcılar, zumbanın hayatın rutinlerinden koparak kendilerini aktif ve bir gruba bağlı hissettirdiği bir aktivite olduğuna vurgu yapmaktadır.

\section{TARTIŞMA ve SONUÇ}

$\mathrm{Bu}$ araştırmada, aktif zumbaya katılan üyelerin zumba kavramına ilişkin sahip olduklanı algılara metaforlar aracilı̆̆ıla ulaşmak amaçlanmıştır. Yapılan çalışmada düzenli zumba yapan bireylerin zumba kavramına ilişkin ürettikleri metafora yönelik açıklama cümleleri incelenmiş olup, katılımcılar tarafindan toplam 35 metafor geliştirilmiştir. Bu metaforlar incelendiğinde, aktif zumba katılımcılarının zumba kavramını birbirinden farklı ve zengin ifadelerle açıladıkları gözlemlenmiştir. Bu kapsamda katılımcılar zumba kavramını frekanslarına göre en fazla eğlence, dans, çikolata, spor, yaşam biçimi ve hayat enerjisi metaforlarına benzetmişlerdir. Zumba kavramına yönelik üretilen 35 tür metafor toplam 93 defa belirtilmiştir. İncelenen bu metaforlar; "psikolojik fayda, sağlık, mutluluk hissi, haz ve sosyalleşme" başlıkları altında 5 farklı kategoride toplanmıştır.

Zumba kavramı için çoğunlukla insanların vakitlerini keyifli bir şekilde geçirmek için yaptıkları çeşitli faaliyetler olan eğlenmek eylemi (eğlence, dans) ile buna paralel olarak negatif duygulardan arınmak, mutlu ve iyi hissetmek gibi psikolojik açıdan bireyin ruh sağlığına fayda sağlayan (hayat enerjisi, yaşam biçimi, spor, çikolata) metaforlar geliştirdikleri saptanmıştır. Bu durumda aktif zumba yapan bireylerin, zumba kavramını beden ve ruh sağlığının birbirini olumlu yönde etkileyen bir bütün oluşturduğunu ve benzer yönleri farklı bakış açlarıyla ifade ettikleri görülmektedir. Bu sonuç, metaforların bir kelime türünü başka bir kelime ile açıklama vurgusunu destekler durumdadır (Lakoff ve Johnson, 2005). Ayrıca, Gök ve ark.,(2019) y1lında zumba katılımcılarının görüşlerine yönelik yaptığı çalışmada katılımcıların zumbanın eğlenceli ve keyifli yönüne vurgu yaparak, ruh sağlığına etkisi ile ilgili 'Çok eğlenceliydi. Gayet keyif aldım. Kesinlikle keyif aldım' ve 'Ruhen kendimin geliştiğini ve rahatladığını hissettim.' açılamaları çalışmamızdaki bireylerin ürettikleri metaforları destekler niteliktedir.

Belirlenen metaforlar kategorilere ayrllıp incelendiğinde; aktif zumba yapan bireylerin bakış açıları daha net bir şekilde anlaşılmaktadır; 
Ceylan, G., \& Kozak, M. (2021). Aktif zumbaya katılan üyelerin "zumba” kavramına ilişkin algıları: Bir metafor analizi çalışmasi. Journal of Human Sciences, 18(2), 233-242. doi:10.14687/jhs.v18i2.6149

"Psikolojik fayda" kategorisinde aktif zumba yapan bireyler toplam 12 metafor üretmişlerdir. Üretilen bu metaforların özgüven, terapi, antidepresan, deşarj, kafa dağıtmak, tutku, doping, yaşam zevki biçiminde sıralandığ belirlenmiştir. Belirlenen bu metaforlardan hareketle literatürde, zumbaya katılmanın toplum temelli fiziksel aktivite ve psikososyal sağlı̆ın teşviki ve gelişimi açısından etkili olduğu, duygusal durumda iyileşmeyi desteklediği, depresyon seviyelerini ve psikolojik stresi azaltarak bireylerin refah seviyelerinin yükselmesine katkı sağladığ1 (Domene ve ark., 2016a) ifade edilmiştir.

"Sağlık" kategorisinde aktif zumba yapan bireyler toplam 10 metafor üretmişlerdir. Üretilen bu metaforların spor, zayıflamak, sağlık, temel ihtiyaç, seratonin hormonu biçiminde sıralandığ1 belirlenmiştir. Bu durumda zumbaya aktif katılım gösteren bireyler, zumba kavramını ruhen ve fiziken de iyi olma hali olan sağlık ile ifade ettikleri görülmektedir. Domene ve arkadaşları (2016b), zumba fitness'ın sağlığı geliştirici etkisini inceledikleri çalışmalarında fiziksel işlevsellik, genel sağlık, enerji / yorgunluk ve duygusal iyilik halinde büyük bir artış gözlemlediklerini ve zumbanın sağlığ1 geliştirici bir özellikte olduğunu ifade etmişlerdir. Ayrıca zumba uygulamasının sağlık ile ilgili birçok faydasının olduğunu, Krishnan ve ark. (2015), obez ve tip 2 diyabetik kadınlarda yaptığı çalışmada, zumba müdahalesinin sağlı̆̆1 ve fiziksel zindeliği iyileştirdiğini ifade etmişlerdir. Samy ve ark. (2019), birincil dismenoreli hastalarda ağrının şiddeti ve süresi üzerindeki etkinliğini inceledikleri araştırmada, 8 haftalık zumba uygulamasının menstrüel ağrı yoğunluğunu, kontrol grubuna kıyasla önemli ölçüde azalttı̆̆ı sonucuna ulaşmışlardır. Barranco-Ruiz ve Villa-González(2020), sedanter kadın çalışanlarda yaptıkları araştırmada, zumba egzersizinin sağlıkla ilgili fiziksel uygunluğu geliştirmek için etkili bir strateji olduğunu belirtmişlerdir. Vendramin ve ark. (2016), “zumbafitness eğitiminin sağlığa faydaları: sistematik bir inceleme” isimli araştırmalarında zumba kondisyonunun aerobik kapasiteyi arttırabilen etkili bir fiziksel aktivite türü olduğunu, vücut ağırlı̆̆ını ve diğer vücut ölçülerini azaltmak için azda olsa olumlu faydalar sağladığını, ayrıca zumba fitness uygulamasından sonra bireylerin yaşam kalitesi üzerinde psikolojik ve sosyal faydalar sağladığını ve kas gücü ile esneklik üzerinde de olumlu etkilerin olduğunu belirtmişlerdir.

"Mutluluk hissi" kategorisinde aktif zumba yapan bireyler toplam 33 metafor üretmişlerdir. Üretilen bu metaforların çikolata, çilek, kahve, tatlı, doğum, göklerde uçmak, motivasyon, canlılık, dans, aradığını bulmak, mutlu olmak, mutluluk yağmuru, su biçiminde sıralandığı belirlenmiştir. Katılımcıların zumba kavramı için ürettikleri metaforlar ve açıklamalarından yola çıkarak, zumbaya katıldıklarındaki duygu durumunu, kendilerini daha keyifli hissettikleri ve mutluluk verici bir unsur olarak gördüklerini belirtmişlerdir. Yapılan aktivitede mutluluk halinin olması, bireyin beden ve ruh sağlığ1 açısından önem arz etmektedir. Bu açıklamalardan yola çıkarak latin müziğini dünya müziği ve dans hareketleriyle bütünleştiren zumba'nın katılımcılar açısından mutluluk, heyecan verici, enerjik bir dans dersi ve etkili bir fitness programı olduğu günümüzde herkes tarafindan bilinmektedir (Gök ve ark. 2019).

"Haz" kategorisinde aktif zumba yapan bireyler toplam 30 metafor üretmişlerdir. Üretilen bu metaforların eğlence, yaşam biçimi, hayat enerjisi, her şey, özgürlük biçiminde sıralandığı belirlenmiştir. Katılımcıların zumba kavramı için bu kategoride üretmiş oldukları metaforlar incelendiğinde zumbanın hoşlarına giden bir duyguyu uyandırdığı, yapılan aktiviteden memnun olduklarını ve keyif aldıklarını anlamak mümkündür. Buradan hareketle zumba aktivitesi, sürdürülmesi istenen olumlu ve insan ruhuna doygunluk veren, coşkunun dile gelimi olan haz duygusuna katkı sağladığı düşünülmektedir.

"Sosyalleşme" kategorisinde aktif zumba yapan bireyler toplam 9 metafor üretmişlerdir. Üretilen bu metaforların hobi, oyun, arkadaş, aktivite biçiminde sıralandığ1 belirlenmiştir. Katılımcıların ürettiği metaforlardan da anlaşılacağı gibi zumba'nın; bireyin yeni kişilerle tanışarak arkadaşlık kurmasını ve kendilerini bir gruba ait hissetmesini sağlayan bir algı yarattığını, bu sayede sosyalleşmeyi sağladığını ifade etmişlerdir. Gök ve arkadaşlarının (2019), çalışmasında zumbanın sosyalliğe katkı sağladığı ile ilgili bireyin 'Sosyalleştim. Sosyalleşme konusunda bana birçok faydası oldu. Sosyallik anlamında hayatımı etkilediğini düşünüyorum.' ifadesi metaforumuzu destekler niteliktedir. 
Ceylan, G., \& Kozak, M. (2021). Aktif zumbaya katılan üyelerin "zumba” kavramına ilişkin algıları: Bir metafor analizi çalışması. Journal of Human Sciences, 18(2), 233-242. doi:10.14687/jhs.v18i2.6149

Sonuç olarak, aktif zumbaya katılan bireylerin ifade ettikleri 35 metafor katılımcıların zumba kavramına olan bakış açılarını göstermiş olup, 5 grup içerisinde kategorize edilmiştir. Bu gruplar her ne kadar özerk başlıklar altında kategorize edilerek sunulmuş olsa da aslında sistematik bir şekilde bağımlı bir yapıyı belirtmektedir. Dolayısıyla metaforlarla oluşturulan "Psikolojik Fayda", "Mutluluk Hissi", "Haz" kategorileri katılımciların zumba kavramını "Duygu Durumu" ile özdeşleştirdikleri şeklinde yorumlanabilir. Ayrıca beden, ruh ve iyi olma hali olan "Sağlık" ve ömür boyu süren öğrenme sürecine eşlik eden "Sosyalleşme" kavramlarının da çalısmanın sonucunda oluşturulan gruplanı bütünleyici bir anlam içerdiği söylenebilir. Araştırma bir bütün olarak değerlendirildiğinde aktif zumba yapan bireylerin, zumba kavramına ilişkin belirtmiş oldukları metaforlardan yola çıarak, zumba kavramına yönelik algılarının olumlu olduğu sonucunu ortaya koymaktadır.

\section{KAYNAKÇA}

Adaş, S. D., Dursun, M., Arı, Ç., Ulun, C. (2020). Spor örgütlerinde çalışan personelin yönetici kavramına iliškin metaforike algzları. Oktay Kızar (Ed.), Spor Bilimleri Alanında Araştırma Makaleleri İçinde (s.179-197). Ankara: Gece Akademi.

Altay, F., Bulca, Y. (2006). Ritim Eğitimi ve Dans, 1.Bask1, Spor yayınevi ve Kitabevi, Ankara, s: 1113.

Barranco-Ruiz, Y., Villa-González, E. (2020). Health-related physical fitness benefits in sedentary women employeesafter an exercise intervention with zumba fitness. Int J Environ Res Public Health. 11;17(8): DOI: 10.3390/ijerph17082632.

Bayköse, N., Ceylan, G., Yazıc1, A. (2021). A metaphor: does covid-19 is an obstacle for adolescent athletes? International Journal of Life Science and Pharma Research. SP 14: 204-210.

Büyüköztürk Ş., Kılıç Çakmak, E., Akgün, Ö. E., Karadeniz, Ş. Ve Demirel, F. (2009). Bilimsel araștrma yöntemleri. Ankara: Pegem A.

Creswell, J. W. (2013). Araștırma deseni: nicel, nitel ve karma yöntem yaklaşımlar (S. B. Demir, Çev.). Ankara: Eğiten Kitap.

Creswell JW. (2020). Nitel araştırma yöntemleri. Beş yaklaşıma göre nitel araştırma ve araştırma deseni. (Çev Edit: Demir, SB \& Bütün, M). Ankara: Siyasal Kitapevi. s.157.

Cugusi, L., Manca, A., Bergamin, M., Blasio, A. D., Yeo, T. J., Crisafulli, A., Mercuro, G. (2019). zumba fitness and women's cardiovascular health: a systematic review. Journal of Cardiopulmonary Rebabilitation and Prevention. 39(3): 153-160. doi: 10.1097/HCR.0000000000000326.

Domene, P. A., Moir, H. J., Pummell, E., Easton, C. (2016a). Salsa dance and zumba fitness: acute responses during community-based classes. Journal of Sport and Health Science 5(2): 190-196.

Domene, P. A., Moir, H. J., Pummell, E., Knox, A., Easton, C. (2016b). The health-enhancing efficacy of zumba fitness: an 8-week randomised controlled study. Journal of Sports Sciences 34(15): 1396-1404. doi: 10.1080/02640414.2015.1112022.

Dursun, M., Ar1, C.., Adaş, S. K., Ulun, C. (2019). Spor örgütlerinde çalssan bireylerin lider kavramma ilişkin metaforik algular. Oktay Kızar (Ed.), Spor Bilimleri Alanında Araştırma Makaleleri İçinde (s.199-214). Ankara: Gece Akademi.

Gök, D., Özbal, A. F., Ak, D. (2019). Kastamonu üniversitesi öğrencilerinin zumba katıllımları ile ilgili görüşleri. IspesJournel. 2(2): 1-12. ISSN:2667-4777.

Kozak, M., Bayrakdar, A., Karaman, M., and Zorba, E. (2020). Determination of the perceptions of individuals engaged in regular physical activity on the concept of wellness: A metaphor analysis study. African Educational Research Journal, 8(1): S43-S48. DOI: 10.30918 / AERJ.8S1.20.006.

Krishnan, S., Tokar, T. N., Boylan, M. M., Griffin, K., Feng, D., Mcmurry, L., Esperat, C., Cooper, J. A. (2015). Zumba dance improves health in over weight/obese or type 2 diabetic women. American Journal of Healty Behavior. 39(1): 109-120. DOI: 10.5993/AJHB.39.1.12 
Ceylan, G., \& Kozak, M. (2021). Aktif zumbaya katılan üyelerin "zumba” kavramına ilișkin algıları: Bir metafor analizi çalışması. Journal of Human Sciences, 18(2), 233-242. doi:10.14687/jhs.v18i2.6149

Kurtipek, S. (2019). Spor kulüplerine üye bireylerin spor kulübü kavramına ilişkin algılarının belirlenmesi: bir metafor analizi çalssmasi. Spormetre 17(1): 209-145. DOI: $10.33689 /$ spormetre.474481

Kurtipek, S., Çelik, O. B., Gümüş, H., Yılmaz, B. (2017). Metaphorical perceptions of campleaders working under theministry of you thand sports on the concept of youth. Ovidius University Annals, Series Physical Education and Sport Science, Movement and Health, 17(2), 359-368.

Kurtipek, S. \& Güngör, N. B. (2018). Determination of thePerceptions of Sport Manager CandidatesRelated on theConcept of Manager: A Metaphor Analysis Study. International Journal of HigherEducation, 7(5), 158-166.

Kurtipek, S. \& Güngör, N. B. (2019a). Determination of theperceptions of sportmanagers on the concept of organization: A metaphoranalysisstudy. Journal Of Educationand Training Studies, 7(2), 57-63.

Kurtipek S. \& Güngör N., B.(2019b). Perception of TrainersfortheAthlete. TurkishJournal of SportandExercise, 21(2), 379-385.

Kurtipek, S. \&Sönmezoglu, U. (2018). Determination of theperceptions of sports managersabout sportconcept: a metaphoranalysisstudy. International Journal of HigherEducation, 7(4), 17-25.

Lakoff, G., Johnson, M. (2005). Metaforla;: hayat, anlam ve dil (Çev. G. Y. Demir). İstanbul: Paradigma. Luettgen, M., Foster, C., Doberstein, S., Mikat, R., Porcari, J. (2012). Zumba: is the "fitness-party" a good workout? Journal of Sports Science and Medicine. 11(2): 357-358. PMC3737860.

Miles, M. B. ve Huberman, A. M. (1994). Qualitative data analysis: An expandedsourcebook. Sage.

Patton, MQ. (2014). Nitel analiz ve yorumlama. (Edit.; Çekiç A, \& Bakla A.). Ankara: Pegem Akademi. S.505.

Patton, MQ. (2014). Nitel araștrma ve değerlendirme yöntemleri. (ÇevEdit.; Bütün, M \& Demir, S. B.). Ankara: Pagem Akademi.

Samy, A., Zaki, Ș. S., Metwally, A. A., Mahmud, D. S., Elzahaby, I. M., Amin, A. H., Eissa, A. İ., Abbas, A. M., Hüseyin, A. H., Talaat, B., Ali, A. S. (2019). The effect of zumba exercise on reducing menstrual pain in young women with primary dysmenorrhea: a randomized controlled trial. J Pediatr Adolesc Gynecol. 32(5): 541-545. DOI: 10.1016 / j. jpag.2019.06.001.

Schneekloth, B., Brown, G. A. (2018). comparison of physical activity during zumba with a human or video game instructor. International Journel of Exercise Science. 11(4): 1019-1030. PMC6102192.

Spandler, H., Mckeown, M., Roy, A., Hurley, M. (2013). Football metaphor and mental well-being: An evaluation of theIt's a Goal! programme. Journal of Mental Health, 22(6), 544554.doi.org/10.3109/09638237.2013.819420

Vendramin, B., Bergamin, M., Gobbo, S., Cugusi, L., Duregon, F., Bullo, V., Zaccaria, M., Neunhaeuserer, D., Ermolao, A. (2016). Health benefits of zumba fitness training: a systematic review. The Journel of Injury, Function, and Rehabilitation. 8(12):1181-1200. DOI: 10.1016/j.pmrj.2016.06.010

Yıldırım, A. ve Şimşek, H. (2014). Sosyal bilimlerde nitel araşsırma yöntemleri (Genişletilmiş 9. Baskı). Ankara: Seçkin Yayınları.

\section{Extended English Summary}

Dance has a structure that provides the development of rhythm ability with basic physical movement and music education (Altay \& Bulca, 2006), covers both learning and performance elements of the person, and is also academically under the umbrella of sports and exercise sciences both in our country and in the world. Therefore, dance as a concept intertwined with sports is associated with many fields, especially exercise (Gök et al., 2019).

Zumba, soca, samba, salsa, merengue and mambo is a fitness routine that includes music and dance moves that combine Latin rhythms with different movements, fun and vitality (Schneekloth \& Brown, 2018). The well-known and lifestyle exercise zumba is a Latin-inspired 
Ceylan, G., \& Kozak, M. (2021). Aktif zumbaya katılan üyelerin “zumba” kavramına ilişkin algıları: Bir metafor analizi çalışması. Journal of Human Sciences, 18(2), 233-242. doi:10.14687/jhs.v18i2.6149

dance exercise developed in Columbia in the mid-1990s by renowned fitness instructor Alberto "Beto" Perez. Zumba was actually developed "by accident" when one day Beto forgot to bring his traditional aerobic music to the classroom (Luettgenand et al., 2012).

Phenomenology design was used in this study, which was prepared according to the qualitative research model. The phenomenology pattern focuses on phenomena that we are aware of but do not have an in-depth and detailed understanding (Creswell, 2013; Yıldırım \& Şimşek, 2014).

While forming the study group, criterion sampling, one of the purposeful sampling methods, was used. (Büyüköztürk, Kılıç Çakmak, Akgün, Karadeniz, \& Demirel, 2009) Critical sampling is the study of situations that meet a predetermined set of criteria. Criteria or criteria can be created by the researcher (Yıldırım \& Şimşek, 2014). The study group of the study consisted of 93 individuals who live in Ankara with an average age of $32.57 \pm 9.91$ and actively engage in zumba in various sports halls. Data collection was carried out by taking into account criteria such as the volunteer participation of the participants in the study.

In order to collect data in the study, a "metaphor form" was prepared to determine the participants' perceptions about the concept of zumba. This form is like "Zumba..." from the participants; Because the semi-structured questionnaire form was used, in which they were asked to complete the sentence of...".

Since the metaphors obtained in the research were used as a descriptive tool, content analysis, one of the qualitative research approaches, was used in analyzing the data. Content analysis is the process of defining, coding and categorizing data (Patton, 2014). In order to start the analysis of the data, first of all, the forms of the participants are numbered from K1 to K93. Evaluating and interpreting the metaphors stated by the participants in the research with content analysis; elimination, compilation, ensuring validity and reliability, calculating and categorizing the frequencies of metaphors. In order to ensure the reliability of the research, the data were analyzed by 3 experts in order to determine whether the conceptual categories reached as a result of the data analysis represent the themes obtained; The codes obtained and the categories represented by the codes were compared. After the research data were coded separately by 3 researchers, the resulting code and category list was finalized. Reliability of data analysis done in this way; It was calculated using the formula [Agreement / (Agreement + Disagreement) x 100] (Miles \& Huberman, 1994). A total of 35 metaphors were produced in the study, and 1 metaphor (water) with a difference of opinion among 94 opinions was determined. The average reliability between coders was found to be $97 \%[34 /(34+1) \times 100=97 \%]$. This result shows that the desired reliability level has been reached in the study.

As a result, 35 metaphors expressed by individuals participating in active zumba showed the participants' perspectives on the concept of zumba and were categorized into 5 groups. Although these groups are categorized under autonomous headings, they actually indicate a systematically dependent structure. Therefore, the categories of "Psychological Benefit", "Sense of Happiness", "Pleasure" created by metaphors can be interpreted as the participants associate the concept of zumba with "Emotional State". In addition, it can be said that the concepts of "Health", which are body, spirit and well-being, and "Socialization" that accompany the lifelong learning process, have a complementary meaning for the groups formed as a result of the study. When the research is evaluated as a whole, it reveals that the perceptions of the participants towards the concept of zumba are positive, based on the metaphors that individuals who make active zumba have stated about the concept of zumba. 